\title{
GAMBARAN KARAKTERISTIK IBU BERSALIN DENGAN KETUBAN PECAH DINI DI RUMAH SAKIT UMUM DAERAH BALARAJA TANGERANG
}

\author{
Putri Handayani Setyaningsih \\ Program Studi D3 Kebidanan, STIKes Widya Dharma Husada Tangerang \\ Jalan Pajajaran No1, Pamulang Tangerang Selatan Banten \\ putrihandayanisetyaningsih@wdh.ac.id
}

\begin{abstract}
ABSTRAK
Latar Belakang, Jumlah kematian ibu di dunia pada tahun 2015 mencapai 303.000 orang dan jumlah kematian ibu akibat komplikasi kehamilan dan persalinan di dunia sebanyak 216/100,000 kelahiran hidup, Secara Epidemiologi, keberhasilan upaya kesehatan ibu diantaranya dapat dilihat dari indikator angka kematiab ibu (AKI) (Kementrian Kesehatan RI, 2016).Tujuan penelitian, ini untuk mengetahui distribusi frekuensi gambaran karakteristik ibu bersalin dengan ketuban pecah dini berdasarkan umur, pendidikan, pekerjaan dan paritas. Rancangan Penelitian, jenis penelitian ini adalah penelitian deskriptif. Teknik sampling yang digunakan dalam penelitian ini adalah Probability Sampling dengan metode Simple Random Sampling dengan jumlah populasi 178 orang dan didapatkan sampe sebanyak 64 orang. Jenis data yang digunakan yaitu data sekunder yaitu berupa data rekam medik di Rumah Sakit Umum Daerah Balaraja . Analisa data, yang digunakan adalah analisa univariat. Hasil penelitian, didapatkan bahwa ibu bersalin yang mengalami ketuban pecah dini sebanyak 178 orang (44,9\%), berdasarkan umur sebagian besar terjadi pada wanita berusia 20-35 tahun sebanyak 54 orang $(84,38 \%)$, berdasarkan pendidikan sebagian besar berpendidikan menengah sebanyak 50 orang $(78,13 \%)$, berdasarkan pekerjaan lebih dari setengahnya terjadi pada ibu tidak bekerja sebanyak 34 orang $(53,12 \%)$, berdasarkan paritas setengahnya terjadi pada ibu dengan primipara sebanyak 32 orang (50\%). Kesimpulan dan Saran, dengan adanya penelitian ini maka menjadi suatu hal yang penting bagi tenaga kesehatan untuk menyampaikan kepada ibu bersalin tentang kejadian ketuban pecah dini saat ibu masih dalam masa kehamilan.
\end{abstract}

Kata Kunci : Ibu Bersalin; Ketuban Pecah Dini

\begin{abstract}
Background: The number of maternal deaths in the world in 2015 reaches 303,000 people and the number of maternal deaths due to pregnancy and childbirth complications in the world are 216 / 100,000 live births. Epidemiologically, the success of maternal health efforts can be seen from indicator of maternal mortality (AKI) (Ministry of Health, 2016). The purpose of this study was to determine the frequency distribution of the characteristics of maternal mothers with premature rupture of membranes by age, education, occupation and parity. Research design, this type of research is descriptive research. Sampling technique used in this research is Probability Sampling with Simple Random Sampling method with population of 178 people and got until 64 people. Type of data used is secondary data that is in the form of medical record data RSUD Balaraja Hospital. Data analysis, used is univariate analysis. The result of the study found that maternal mothers who experienced premature rupture of membranes as many as 178 people (44.9\%), based on age mostly occurred in women aged 20-35 years as many as 54 people (84.38\%), based on education mostly educated medium as many as 50 people $(78,13 \%)$, based on work more than half happened to mother do not work as many as 34 people $(53,12 \%)$, parity parity half happened to mother with primipara counted 32 people (50\%). Conclusions and Suggestions, with this research it becomes an important thing for health workers to convey to the mother about the incidence of membrane rupture early when the mother is still in pregnancy.
\end{abstract}

Keywords: Maternity Mother; Premature rupture of membranes 


\section{PENDAHULUAN}

Kematian ibu masih merupakan masalah terbesar yang dihadapi berbagai negara terutama negara berkembang. Salah satu penyebabnya adalah disebabkan oleh ketuban pecah dini (WHO, 2014). Jumlah kematian ibu di dunia pada tahun 2015 tercatat sebanyak 303.000 orang dan jumlah kematian ibu akibat komplikasi kehamilan dan persalinan di dunia sebanyak 216 orang (WHO), 2015).

Berdasarkan data yang didapatkan dari Survei Penduduk Antar Sensus (SUPAS) pada tahun 2015 AKI mengalami penurunan yaittu dari 359/100.000 kelahiran hidup menjadi 305/100.000 kelahiran hidup. Data yang didapatkan dari Kementerian Kesehatan Republik Indonesia pada trimester pertama terdapat sebanyak 1.712 kasus kematian ibu pada saat proses persalinan.

Pada tahun 2013 angka kematian ibu di provinsi Banten berjumlah 216/100.000 kelahiran hidup. Kematian ibu di provinsi Banten disebabkan oleh perdarahan 58 orang $(26,8 \%)$, pre eklamsia dan eklamsia sebanyak 77 orang $(35,6 \%)$, infeksi sebanyak 20 orang $(9,2 \%)$, partus lama sebanyak 2 orang $(0,9 \%)$ dan ketuban pecah dini sebanyak 59 orang $(27,3 \%)$ (BKKBN, 2014).
Beberapa penelitian membuktikan bahwa masih tingginya kasus kejadian ketuban pecah dini yang terjadi pada ibu bersalin disebabkan salah satu faktornya adalah kurangnya pengetahuan yang didapat oleh ibu. Karena itu, peneliti tertarik ingin membahas tentang "Gambaran Karakteristik Ibu Bersalin Dengan Ketuban Pecah Dini Di rumah Sakit Umum Daerah Balaraja Periode Juli - Desember Tahun 2018”.

\section{METODE PENELITIAN}

Penelitian ini termasuk penelitian deskriptif. Teknik pengambilan sampel dalam peneitian ini dilakukan dengan cara Probability Sampling dengan metode Simple Random Sampling. Populasi penelitian ini adalah jumlah ibu bersalin yang mengalami ketuban pecah dini di Rumah Sakit Umum Daerah Balaraja periode Juli - Desember 2018 sebanyak 178 ibu bersalin. Sampel pada penelitian ini berjumlah $64 \mathrm{ibu}$ bersalin. Alat/Instrumen penelitian ini menggunakan lembar checklist yang berisi data dari rekam medik ibu bersalin yang mengalami ketuban pecah dini di Rumah Sakit Umum Daerah Balaraja periode Juli Desember 2018. Prosedur pengumpulan data dilakukan dengan 
cara mencari data di ruangan rekam medik Rumah Sakit Umum Daerah Balaraja yang merupakan dokumen asli yang berisi berupa tabel atau daftar periksa pasien. Analisa data yang digunakan dalam penelitian ini adalah analisa univariat.

\section{HASIL DAN PEMBAHASAN}

Hasil penelitian ini berupa hasil analisis univariat.

\section{Analisis Univariat}

Analisis univariat dilakukan untuk menjelakan distribui frekuensi dan persentase dari masing-masing variabel meliputi umur, pendidikan, pekerjaan, paritas.

Tabel 4.1. Distribusi Frekuensi Persalinan Dengan Ketuban Pecah Dini Di RSUD Balaraja Periode Juli - Desember 2018

\begin{tabular}{ccc}
\hline $\begin{array}{c}\text { Jenis } \\
\text { Persalinan }\end{array}$ & Frekuensi & Presentase \\
\hline Tidak KPD & 218 & $55,1 \%$ \\
\hline $\begin{array}{c}\text { Dengan } \\
\text { KPD }\end{array}$ & 178 & $44,9 \%$ \\
\hline Total & 396 & $100 \%$ \\
\hline
\end{tabular}

Berdasarkan tabel 4.1
menunjukkan bahwa dari 396 persalinan hampir setengahnya persalinan mengalami kejadian ketuban pecah dini terdapat 178 kasus $(44,9 \%)$ dan lebih dari setengahnya adalah persalinan normal dan dengan berbagai kasus seperti pre eklamsia, anemia, perdarahan, preterm, hipertensi, dan lain-lain.

Tabel 4.2. Distribusi Frekuensi Persalinan dengan KPD Berdasarkan Umur di RSUD Balaraja Periode Juli - Desember 2018

\begin{tabular}{ccc}
\hline $\begin{array}{c}\text { Kategori } \\
\text { Umur }\end{array}$ & Frekuensi & Presentase \\
\hline$<20$ tahun & 2 & $3,13 \%$ \\
\hline $\begin{array}{c}20-35 \\
\text { tahun }\end{array}$ & 54 & $84,37 \%$ \\
\hline$>35$ tahun & 8 & $12,5 \%$ \\
\hline Total & 64 & $100 \%$ \\
\hline
\end{tabular}

Berdasarkan tabel 4.2 menunjukkan bahwa dari 64 sampel persalinan dengan ketuban pecah dini, sebagian besar persalinan dengan ketuban pecah dini terjadi pada ibu usia 20-35 tahun sebanyak 54 orang $(84,37 \%)$. Karena pada usia 20-35 tahun banyak ibu kurang mengetahui tentang komplikasi yang terjadi pada persalinan khususnya kejadian Ketuban Pecah Dini, serta banyak ibu dengan usia 20-35 tahun tergolong ibu yang baru melahirkan sebanyak satu kali yang mungkin kurang memperhatikan keadaan dirinya pada saat hamil. Dalam hal ini terdapat kesenjangan antara hasil penelitian dan teori menurut Wiknjosastro (2006) bahwa umur ibu pada saat hamil merupakan salah satu faktor yang menentukan tingkat resiko kehamilan dan persalinan.

Dalam hal ini kesenjangan antara teori dan hasil penelitian, didukung oleh 
Muntoba, dkk (2013) tentang faktorfaktor yang mempengaruhi kejadian Ketuban Pecah Dini di RS. Telogorejo Semarang, dimana hasil penelitian tersebut menunjukan bahwa umur 20-35 tahun merupakan usia reproduksi yang sehat dan aman untuk kehamilan dan persalinan. Selain itu, kejadian Ketuban Pecah Dini tidak hanya dilihat dari satu penyebab, karena penyebab pada Ketuban Pecah Dini belum dapat dipastikan, ada banyak faktor yang bisa menyebabkan Ketuban Pecah Dini. Ibu yang berusia reproduktif 20-35 tahun memiliki faktor lain yang dapat menyebabkan terjadinya Ketuban Pecah Dini seperti panggul sempit, riwayat Ketuban Pecah Dini sebelumnya, dan sebagian besar ibu dengan usia 20-35 tahun tergolong kategori ibu primipara atau pernah melahirkan sebanyak satu kali.

Tabel 4.3. Distribusi Frekuensi Persalinan dengan KPD Berdasarkan Pendidikan di RSUD Balaraja Periode Juli - Desember 2018

\begin{tabular}{ccc}
\hline $\begin{array}{c}\text { Kategori } \\
\text { Pendidikan }\end{array}$ & Frekuensi & Presentase \\
\hline Dasar & 1 & $1,56 \%$ \\
\hline Menengah & 50 & $78,13 \%$ \\
\hline Tinggi & 13 & $20,31 \%$ \\
\hline Total & 64 & $100 \%$ \\
\hline
\end{tabular}

Berdasarkan tabel $\quad 4.3$ menunjukkan bahwa dari 64 orang sampel ibu bersalin dengan Ketuban Pecah Dini, sebagian besar terjadi pada ibu dengan pendidikan menengah terdapat sebanyak 50 orang $(78,13 \%)$. Pengetahuan seseorang dipengaruhi oleh pendidikan seseorang maka semakin baik pengetahuan dan lebih luas dibandingkan tingkat pendidikan rendah (Notoatmodjo, 2010).

Hasil penelitian Angga Widnya (2013) tentang gambaran ketuban pecah dini pada kehamilan aterm Di RSUP Sanglah Denpasar didapatkan hasil yang bahwa ibu dengan pendidikan menengah (SMA) banyak yang mengalami kejadian Ketuban Pecah Dini. Hal ini mungkin dikarenakan kurangnya pengetahuan pasien tentang komplikasi dari persalinan yang salah satunya adalah ketuban pecah dini. Karena tingkat pendidikan seseorang tidak dapat menjamin tingkat pengetahuan seseorang pula.

Jika dibandingan dengan teori yang ada, pada penelitian ini terdapat suatu kesenjangan antara teori dengan hasil penelitian, menurut teori Notoatmodjo (2010), pengetahuan seseorang dipengaruhi oleh pendidikan seseorang maka semakin baik pengetahuan dan lebih luas dibandingkan tingkat pendidikan rendah. Hal ini dapat terjadi karena tidak semua orang yang berpendidikan tinggi pengetahuannya 
pun tinggi, pencarian ilmu pengetahuan antara yang berpendidikan dan tidak berpendidikan itu sama, tergantung diri seseorang untuk mendapatkan pengetahuan tersebut, karena ilmu pengetahuan bisa didapatkan melalui pancaindera yang artinya pengetahuan tidak hanya didapat melalui bangku pendidikan, bisa melalui internet, buku, surat kabar, berita bahkan percakapan dengan orang lain yang mengetahui tentang suatu hal. Pendidikan tidak bisa digunakan untuk menggambarkan pengetahuan seseorang.

Tabel 4.4.Distribusi Frekuensi Persalinan dengan KPD Berdasarkan Pekerjaan di RSUD Balaraja Periode Juli - Desember 2018

\begin{tabular}{ccc}
\hline Umur & Jumlah & Presentase \\
\hline$<20$ tahun & 1 & $2,9 \%$ \\
\hline $\begin{array}{c}20-35 \\
\text { tahun }\end{array}$ & 33 & $94,2 \%$ \\
\hline$>35$ tahun & 1 & $2,9 \%$ \\
\hline Jumlah & 35 & $100 \%$ \\
\hline
\end{tabular}

Berdasarkan tabel $\quad 4.4$ menunjukkan bahwa dari 64 sampel ibu bersalin dengan ketuban pecah dini, lebih dari setengahnya terjadi pada ibu yang bekerja terdapat 34 orang $(53,12 \%)$. Sesuai dengan penjelasan menurut Prawirohardjo (2010), pekerjaan yang terlalu berat pada ibu hamil bisa menyebabkan abortus pada usia kehamilan muda, dan persalinan preterm

(persalinan preterm salah satu penyebabnya adalah Ketuban Pecah Dini).

Dalam penelitian Suryani (2012) tentang gambaran karakteristik kejadian ibu bersalin di RSUD Yogyakarta mengatakan pola pekerjaan ibu hanil berpengaruh terhadap kebutuhan energi. Kerja fisik pada saat hamil yang terlalu berat dan dengan lama kerja melebihi tiga jam perhari dapat berakibat kelelahan. Kelelahan dalam bekerja menyebabkan lemahnya korion amnion sehingga timbul Ketuban Pecah Dini.

Tabel 4.5. Distribusi Frekuensi Persalinan dengan KPD Berdasarkan Paritas di RSUD Balaraja Periode Juli Desember 2018

\begin{tabular}{ccc}
\hline Jumlah Paritas & $\begin{array}{c}\text { Frekuen } \\
\text { si }\end{array}$ & $\begin{array}{c}\text { Presentas } \\
\text { e }\end{array}$ \\
\hline Primipara & 32 & $50 \%$ \\
\hline Multipara & 30 & $46,88 \%$ \\
\hline Grandemultipara & 2 & $3,12 \%$ \\
\hline Total & 64 & $100 \%$ \\
\hline
\end{tabular}

Berdasarkan tabel 4.5
menunjukkan dari 64 orang sampel
persalinan dengan Ketuban Pecah Dini,
setengahnya terjadi pada ibu primipara
yaitu sebanyak 32 orang (50\%), ini
dikarenakan banyak ibu primipara yang
belum mengerti dengan perubahan yang
terjadi pada dirinya saat hamil sehingga
menganggapnya hal biasa saja. Hal ini


menunjukkan kesesuaian dengan teori Manuaba (2007) karena pada teori ini menjelaskan bahwa pada kehamilan pertama wanita belum mengerti dengan perubahan yang terjadi pada dirinya selama hamil, sedangkan pada grandemultipara (wanita yang telah melahirkan lebih dari 5 orang anak atau

\section{KESIMPULAN DAN SARAN}

Berdasarkan hasil penelitian di Rumah Sakit Umum Daerah Balaraja periode Juli

- Desember 2018 dapat disimpulkan sebagai berikut :

1. Distribusi frekuensi ibu bersalin dengan ketuban pecah dini berdasarkan umur di Rumah Sakit Umum Daerah Balaraja periode Juli Desember 2017 sebagian besar terjadi pada usia 20-35 tahun yaitu sebanyak 54 orang $(84,38 \%)$, dan sebagian kecil terjadi pada ibu yang berusia <20 tahun sebanyak 2 orang $(3,13 \%)$ dan ibu berusia $>35$ tahun sebanyak 8 orang $(12,5 \%)$.

2. Distribusi frekuensi ibu bersalin dengan ketuban pecah dini berdasarkan tingkat pendidikan ibu di Rumah Sakit Umum Daerah Balaraja periode Juli - Desember 2018 sebagian besar terjadi pada ibu dengan tingkat pendidikan menengah (SMA) sebanyak 50 orang $(78,13 \%)$, dan lebih) merupakan resiko tinggi kehamilan, dan sering disertai dengan komplikaasi karena pada wanita yang sudah melahirkan lebih dari empat kali fungsi organ reproduksinya sudah menurun, maka semakin tinggi risiko Ketuban Pecah Dini.

sebagian kecil terjadi pada ibu dengan tingkat pendidikan tinggi (perguruan tinngi) sebanyak 13 orang $(20,13 \%)$, dan kemungkinan kecil terjadi pada ibu dengan tingkat pendidikan dasar (SD) sebanyak 1 orang $(1,56 \%)$.

3. Distribusi frekuensi ibu bersalin dengan ketuban pecah dini berdasarkan pekerjaan ibu di Rumah Sakit Umum Daerah Balaraja periode Juli - Desember 2018 sebagian besar terjadi pada ibu yang bekerja yaitu terdapat 54 orang $(54,13 \%)$, dan sebagian kecil terjadi pada ibu yang tidak bekerja yaitu sebanyak 30 orang $(46,88 \%)$.

4. Distribusi frekuensi ibu bersalin dengan ketuban pecah dini berdasarkan jumlah paritas ibu di Rumah Sakit Umum Daerah Balaraja periode Juli - Desember 2017 yang setengahnya terjadi ibu primipara sebanyak 32 orang (50\%), sebagian besar terjadi pada ibu multipara sebanyak 30 orang $(46,88 \%)$, dan 
sebagian kecil terjadi pada ibu grandemultipara sebanyak 2 orang $(3,12 \%)$.

Berdasarkan hasil penelitian yang sudah dilakukan, maka saran yang dapat peneliti sampaikan untuk meningkatkan kualitas pelayanan kesehatan, khususnya bagi ibu bersalin dengan kasus ketuban pecah dini di Rumah Sakit Umum Daerah Balaraja periode Juli - Desember 2018 adalah sebagai berikut :

1. Bagi Peneliti

Agar dapat dijadikan sebagai sarana pengaplikasian ilmu yang sudah didapat selama mengikuti pendidikan di perkuliahan dan bahan untuk kajian agar dapat lebih dalam lagi melakukan deteksi dini komplikasi yang terjadi pada ibu hamil khususnya untuk kasus komplikasi yang dapat menimbulkan kejadian ketuban pecah dini pada saat ibu sudah memasuki usia kehamilan di trimester III, sehingga dapat muncul kewaspadaan dan antisipasi serta persiapan untuk pertolongan pada ibu bersalin dengan ketuban pecah dini, dan juga sebagai bahan pertimbangan untuk melakukan penelitian selanjutnya.
2. Bagi Institusi Pendidikan

Agar dapat lebih meningkatkan pembelajaran tentang kasus ibu bersalin dengan ketuban pecah dini dengan menyediakan referensireferensi yang membahas tentang ketuban pecah dini.

\section{Bagi Tempat Penelitian}

Agar dapat meningkatkan pelayanan kesehatan, terutama untuk pelayanan pada ibu hamil atau pelayanan antenatal, khususnya untuk lebih melakukan deteksi sedini mungkin yang merupakan faktor-faktor penyebab terjadinya ketuban pecah dini yang dapat dicegah pada saat masa kehamilan, sehingga dapat menurunkan angka kejadian ketuban pecah dini yang dapat mengakibatkan komplikasi pada ibu serta bayi pada saat proses persalinan.

\section{DAFTAR PUSTAKA}

Arikunto, S. 2010. Prosedur Penelitian Suatu Pendekatan Praktik. Jakarta : PT Rineka Cipta.

BKKBN. 2006. Deteksi dini komplikasi persalinan. Jakarta : BKKBN 
Kemenkes RI. 2017. Survey Demografi dan Kesehatan Indonesia. Angka Kematian Ibu. (diakses pada tanggal 23 April 2018)

Lockhart, Saputra. 2014. Asuhan kebidana kehamilan fisiologis dan patologis. Tangerang Selatan : Binarupa Aksara Publisher

Manuaba, L.B.G. 2012. Pengantar Kuliah Obstetri. Jakarta : EGC

Manuaba, L.B.G. 2008. Buku ajar patologi obstetri untuk mahasiswa kebidanan. Jakarta : EGC

Mubarak, dkk. 2007. Promosi Kesehatan Sebuah Pengantar Proses Belajar Mengajar dalam Pendidikan. Yogyakarta : Gahara Ilmu.

Notoatmodjo, $\quad$ Soekidjo. 2010. Metodologi penelitian kesehatan edisi revisi. Jakarta
Notoatmodjo. 2012. Metodologi penelitian kesehatan. Jakarta

Prawirohardjo, Sarwono. 2010. Ilmu kebidanan. Jakarta : EGC

Prawirohardjo, Sarwono. 2008. Maternal dan Neonatal. Jakarta : EGC

Prawirohardjo, Sarwono. 2014. Ilmu Kebidanan. Jakarta : PT. Bina Pustaka

Saifudin, Abdul Bari, dkk. 2009. Buku Acuan Nasional Pelayanan Kesehatan Maternal dan Neonatal. Jakarta

Sugiyono. 2013. Metode Penelitian Pendidikan. Bandung : CV. Alfabeta.

Wiknjaksastro. 2010. Ilmu Kebidanan. Jakarta : EGC. 